\title{
María Teresa Serafini, Cómo se estudia. La organización del trabajo intelectual. México, Paidós, 2004. (Instrumentos Paidós, 8)
}

Los que nos dedicamos a la enseñanza tenemos siempre en la mente dos preocupaciones: los alumnos y todo lo que compete con nosotros mismos, los maestros.

Por esa razón llama la atención un excelente libro que se ocupa de estos dos temas a la vez y por si fuera poco lo complementa con nociones de teoría del aprendizaje. Así, me permito recomendar a los lectores, sean alumnos o docentes este libro de Técnicas de estudio. E1 libro que pertenece a la colección "Instrumentos Paidós" dirigido por el semiólogo, literato y estudioso de la cultura, Umberto Eco, se encuentra dividido para su consulta en tres partes: 1a primera parte está dedicada a las técnicas del estudio desde el punto de vista del estudiante, la segunda ve todo desde el punto de vista del docente y le proporciona una valiosa ayuda para la organización de su didáctica; la tercera y última parte, pero no por ello menos valiosa, se encarga de la teoría relacionada con las bases del estudio.

A continuación realizo un resumen del contenido de las partes más relevantes de cada una de ellas:

Dentro de la primera parte, destacan las secciones dedicadas al estudiante, como son: la organización del tiempo, la técnica de toma de apuntes y la de mayor interés, ya que considera los nuevos enfoques sobre el tema, la que se ocupa de la lectura. En dicha sección; no sólo el alumno sino cualquier persona interesada, puede conocer las nuevas teorías para abordar la lectura y las diversas formas de obtener provecho de esta actividad. Resulta de gran interés la información proporcionada para el análisis del párrafo, la cual se ilustra a través de varios ejemplos para que resulte comprensible y viable para el alumno. Otra parte de la información relevante de los aspectos de la lectura es la fase de la lectura crítica que se basa en la determinación de los objetivos, la valoración de la autoridad de las fuentes y la distinción de hechos de opiniones. Cierra esta parte dedicada a la lectura, "la lectura como diversión", que sería la conclusión de todo este proceso, y a la cual, según Serafini, debemos llegar para disfrutar de esta actividad en todo su esplendor. A continuación, de la sección dedicada a la lectura, viene una que se ocupa de la preparación de las exposiciones orales en todos sus aspectos: cómo hacer preguntas, cómo afrontar el momento del examen y cómo hacer uso de los recursos visuales para una mejor exposición; el alumno también tiene la oportunidad de conocer las diferencias entre una exposición de carácter escrito y una de carácter oral. Si el alumno tiene la inquietud sobre la preparación de un tema, desde su etapa inicial hasta la 
fase final, este valioso libro también le puede servir de guía, aunque la autora cuenta incluso con un libro expresamente dedicado al desarrollo de este asunto: Cómo redactar un tema, el número 4 de la colección de "Instrumentos Paidós".

Para la segunda parte del libro, Serafini se ocupa de los aspectos relacionados con la docencia y la didáctica, desde el punto de vista del docente. Así, encontramos referencias a todo lo que interviene en la programación para un mejor desarrollo de una clase, y nos hace reflexionar en las capacidades necesarias para el estudio y en la programación didáctica; este capítulo lo cierra una revisión de los métodos de estudio en Estados Unidos. Destacan en esta sección también: los temas relacionados con el aprendizaje y la motivación para el estudio y los consejos de cómo se dicta clase, que contempla los estilos de enseñanza, los tipos de clase, las formas de dictar clase y el papel de la disciplina, que podrían servir, sea como una guía o sea como un resumen, para los nuevos docentes o a los que quieran mantenerse al día sobre la investigación de los aspectos involucrados en la docencia.

Finalmente, la sección que cierra este libro es el de las bases del estudio, que constituye la parte más teórica de este excelente trabajo. Son analizados, desde el punto de vista cognoscitivo, los papeles de la mente como procesador de informaciones, donde se establece una comparación entre la mente humana y el proceso de una computadora para procesar información, con el fin de presentar las diferentes maneras de anali- zar y resolver problemas. La memoria tiene, por supuesto, un lugar en esta parte, ilustrada con las diversas teorías del funcionamiento de la memoria, y el estudio de los tipos de memoria: la de largo y corto plazo. Aparecen a manera de ejemplos, 1os resultados de algunos experimentos sobre la memorización y las razones de por qué olvidamos.

En esta misma sección, Serafini nos presenta algunos modelos para estructurar el conocimiento para ayudarnos a procesar, memorizar y recuperar datos útiles para el aprendizaje; por tanto, nos proporciona algunas bases para la organización de la información por medio de: abstracciones, redes semánticas y estructuras de conocimiento, tales como esquemas o guiones. Casi para finalizar, la autora se enfoca en la función desempeñada por la comprensión, estudiada en su proceso cognoscitivo y analizada en los procesos, primero, de la compresión de los mensajes escritos y segundo, la comprensión del contexto y de cómo se relacionan los nuevos elementos del conocimiento con los ya existentes en nuestra memoria para ayudarnos a una mejor comprensión del mundo y a mejorar nuestro bagaje cognoscitivo.

Serafini concluye este libro con un capítulo centrado en el análisis y la resolución de problemas, de esta manera aprendemos las formas diversas de las técnicas de resolución de problemas, como pueden ser el análisis exhaustivo o la reducción de un problema, es decir nos enseña a ver las diferentes caras que puede tener un problema y su relación con el aprendizaje de nuevos conocimientos. La autora presenta también los aspectos negativos en la resolución 
de un problema, tales como el enfrentamiento de un fracaso o las interrupciones en la resolución de un problema. En este campo se ocupa asimismo del papel de la creatividad para resolver los problemas o la búsqueda de soluciones inusuales.

Como hemos visto, este libro de María Serafín Cómo se estudia. La organización del trabajo intelectual, no es tan sólo un valioso instrumento para alumnos que se inicien en el proceso de adquisición del conocimiento, sino también para los docentes siempre preocupados por aprender, conocer y mejorar su labor docente.

Gustavo Santana

CEPE-UNAM 
